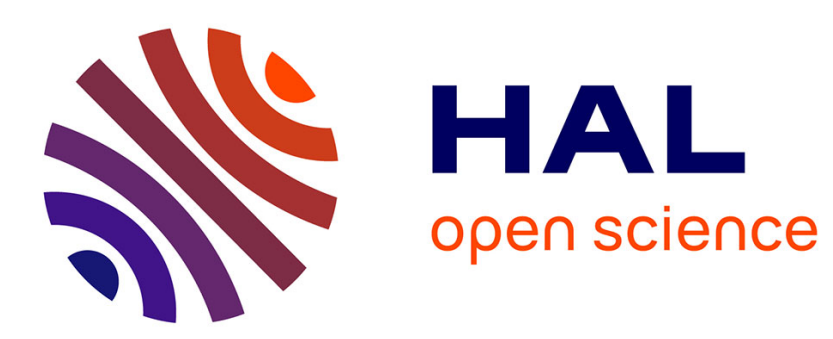

\title{
Uranyl extraction by TBP from a nitric aqueous solution to SC-CO2: MD Simulations of Phase Demixing and Interfacial Systems.
}

Rachel Schurhammer, Georges Wipff

\section{- To cite this version:}

Rachel Schurhammer, Georges Wipff. Uranyl extraction by TBP from a nitric aqueous solution to SC-CO2 : MD Simulations of Phase Demixing and Interfacial Systems.. ACS Symposium Series, 2003, 860, pp.223-244. 10.1021/bk-2003-0860.ch015 . hal-03164479

\author{
HAL Id: hal-03164479 \\ https://hal.science/hal-03164479
}

Submitted on 9 Mar 2021

HAL is a multi-disciplinary open access archive for the deposit and dissemination of scientific research documents, whether they are published or not. The documents may come from teaching and research institutions in France or abroad, or from public or private research centers.
L'archive ouverte pluridisciplinaire HAL, est destinée au dépôt et à la diffusion de documents scientifiques de niveau recherche, publiés ou non, émanant des établissements d'enseignement et de recherche français ou étrangers, des laboratoires publics ou privés. 


\title{
Chapter 15
}

\section{Uranyl Extraction by TBP from a Nitric Aqueous Solution to $\mathrm{SC}-\mathrm{CO}_{2}$ : MD Simulations of Phase Demixing and Interfacial Systems.}

\author{
Rachel Schurhammer and Georges Wipff * \\ Institut de Chimie, 4 rue B. Pascal, 67000 Strasbourg (France) \\ wipff@chimie.u-strasbg.fr
}

In relation with the liquid-liquid extraction of uranyl nitrate from an acidic aqueous phase to supercritical $\mathrm{CO}_{2}$, we present a series of molecular dynamics (MD) simulations on the "interfacial" systems involving $\mathrm{UO}_{2}\left(\mathrm{NO}_{3}\right)_{2}$ species and high concentrations of TBP and nitric acid. We compare the distribution of solvent and solutes at the interface which forms upon the demixing of "chaotic mixtures" of water $/ \mathrm{CO}_{2}$ solutions. The simulations highlight the importance of interfacial phenomena in uranyl extraction to $\mathrm{CO}_{2}$. In most cases, demixing leads to separation of aqueous and $\mathrm{CO}_{2}$ phases which form an interface. At low concentrations, TBP and the neutral form $\mathrm{HNO}_{3}$ of the acid adsorb at the interface, while the uranyl salt and ionic species sit in water. Spontaneous complexation of uranyl salts by TBP is observed, leading to $\mathrm{UO}_{2}\left(\mathrm{NO}_{3}\right)_{2}(\mathrm{TBP})\left(\mathrm{H}_{2} \mathrm{O}\right)$ and $\mathrm{UO}_{2}\left(\mathrm{NO}_{3}\right)_{2}(\mathrm{TBP})_{2}$ species of $1: 1$ and 1:2 stoichiometry, respectively, which adsorb at the interface. As the TBP concentration is increased, the proportion of 1:2 species, more hydrophobic than the $1: 1$ species, increases, following the Le Chatelier principle. Nitric acid competes with the uranyl complexation by TBP which forms hydrogen bonds with $\mathrm{H}_{3} \mathrm{O}^{+}$or $\mathrm{HNO}_{3}$ species. Thus, at high acid:TBP ratio, the concentration of $1: 1$ and 1:2 complexes decreases. Also noteworthy is the evolution of the interface from a well-defined border at low acid and TBP concentrations, to a mixed microscopic "third phase" containing some 1:2 complexes which can be considered as "extracted". We believe that such heterogeneous microphase is important for the stabilization and extraction of uranyl complexes by TBP and, more generally, in the extraction of highly hydrophilic cations (e.g. lanthanides or actinides) to organic media. 


\section{INTRODUCTION}

Supercritical $\mathrm{CO}_{2}$ "SC- $\mathrm{CO}_{2}$ " can be used as a promising ecological alternative in liquid-liquid extraction systems.(1-6) This is of particular interest in the context of nuclear waste partitioning, which is generally initiated from aqueous solutions of the metal ions, obtained by dissolution of the irradiated material in concentrated nitric acid solutions. Examples of metal extraction to $\mathrm{SC}-\mathrm{CO}_{2}$ from solid or liquid matrices involve extraction of metallic, lanthanide and actinide cations by $\beta$ diketonate ligands, (7-9) of strontium by crown ethers $(8)$ or of $\mathrm{UO}_{2}{ }^{2+}, \mathrm{Th}^{4+},(10-$ $15)$ lanthanides $(16,17)$ or heavy metals $(18)$ by organophosphorus ligands. Reviews can be found in ref. $(2,19)$. Recently, a new method for dissolving solid uranyl dioxide in $\mathrm{SC}-\mathrm{CO}_{2}$ with the $\mathrm{CO}_{2}$-philic $\mathrm{TBP} \cdot \mathrm{HNO}_{3}$ complexant without requiring dissolution by acid in water has been reported.(11)

In this paper we focus on the uranyl extraction by TBP (tri- $n$-butylphosphate) in acidic conditions, with the aim to investigate the interfacial behavior of the partners involved in the extraction process to $\mathrm{SC}-\mathrm{CO}_{2}$. As metallic ions are quasi-insoluble in $\mathrm{SC}-\mathrm{CO}_{2}$ while uncomplexed ligands used in liquid-liquid extraction are not soluble in water, it is stressed that the border region ("interface") between the two liquids should play a key role in the transfer of the complexed ions to the $\mathrm{CO}_{2}$ phase. TBP is used in the industrial PUREX process for nuclear waste processing to extract uranyl as $\mathrm{UO}_{2}\left(\mathrm{NO}_{3}\right)_{2}(\mathrm{TBP})_{2}$ complexes (20-24) and also extracts the uranyl cation from acidic aqueous solutions to $\mathrm{SC}-\mathrm{CO}_{2}$. Owing its amphiphilic character, TBP is also surface active and should thus concentrate at the surface of water. Similar features are anticipated for the neutral form $\mathrm{HNO}_{3}$ of nitric acid, which, according to MD simulations $(25,26)$ and surface spectroscopy studies, $(27)$ is also surface active and accumulates at the water/"oil" interfaces, which display marked analogies with the water/air interface.(28) On the other hand, hydrophilic metallic ions are "repelled" by the interface, preventing their capture by water insoluble extractants.(29) It is thus important to understand at the molecular level what happens at the liquid boundaries (30) and we report new microscopic insights into this question obtained from molecular dynamics (MD) simulations with explicit representation of the solvents and solutes.

In our first investigations of water "/oil" extraction systems, the "oil" phase was modeled by chloroform, focusing on the distribution of ligands (e.g. calixarenes, crown ethers, cryptands, podants, CMPO, TBP) and their complexes, as well as all kinds of ionic species.(31-33) Recently, we reported the first MD investigations on water $/ \mathrm{SC}-\mathrm{CO}_{2}$ interfaces, either neat, or in the presence of salts or extractants molecules. $(26,28,34)$ These studies considered $\mathrm{pH}$ neutral systems. Here, we focus on uranyl extraction in acidic conditions. The simulated systems, noted $\mathbf{A}$ to $\mathbf{J}$, are described in Table 1 and Figure 1 . The water $/ \mathrm{CO}_{2}$ interfacial system $\mathbf{A}$ (no solute) and the acidic systems $\mathbf{B}$ and $\mathbf{C}$ (corresponding to about 1 and 2 mol. $\left.\mathrm{L}^{-1}\right)$ have been previously reported $(28,34)$ and are briefly described as references for more complex and concentrated systems. The systems F-J contain 5 
R. Schurhammer and G. Wipff, in Separations and Processes using Supercritical Carbon Dioxide, Ed. A. S. Gopalan, C. Wai, and H. Jacobs (ACS, 2003), Vol. 860, Chap. 15, pp. 223-244.

or $6 \mathrm{UO}_{2}\left(\mathrm{NO}_{3}\right)_{2}$ uranyl salts (about $0.05 \mathrm{~mol} \mathrm{l}^{-1}$ ), and increasing amounts of TBP (from 30 to 120 molecules) and of nitric acid in the simulation box. The 60 TBP solutions $\mathbf{E}, \mathbf{H}$ and $\mathbf{I}$ correspond roughly to the concentration used experimentally in the PUREX process. One important issue in modeling studies concerns the representation of acidity, as force field methods cannot properly account for proton transfer processes, and require an a priori choice of the protonated / deprotonated species. As this is not known from experiment for heterogeneous systems, we decided to model nitric acid as $\left(\mathrm{HNO}_{3}, \mathrm{H}_{3} \mathrm{O}^{+} \mathrm{NO}_{3}^{-}\right)_{m}$, i.e. an equimolar mixture of neutral and ionic forms, which represent the dominant contributions in organic and aqueous phases, respectively. Thus, $m=18$ in systems $\mathbf{F}$ and $\mathbf{H}$ (corresponding to about $1 \mathrm{M}$ aqueous solutions) and $m=36$ in systems $\mathbf{G}$ and $\mathbf{J}$.

The MD simulations D - J focus on the demixing of completely mixed water/ $\mathrm{CO}_{2} / \mathrm{TBP} /$ acid systems, which are "chaotic arrangements", also prepared by MD simulations (see methods). These systems, "perfectly mixed" at the microscopic level (probably more than they are in reality) are highly unstable. We want to investigate how they spontaneously evolve and relax, and in particular to which extent the aqueous and $\mathrm{CO}_{2}$ phases will separate, and how the acid and uranyl nitrate species will distribute once the equilibrium is reached. One critical issue, in relation with assisted extraction, is whether and under which conditions uranyl will be complexed by TBP and finally extracted to $\mathrm{CO}_{2}$. The $\mathrm{pH}$-neutral $\mathbf{D}$ and $\mathbf{E}$ systems, described in more details in ref. (28) are presented here for a purpose of comparison with the acidic ones $\mathbf{F}$ - $\mathbf{J}$.
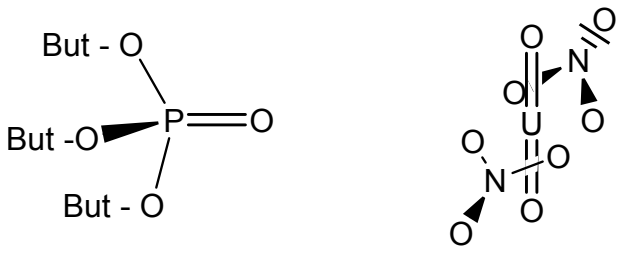

Figure 1. The simulated species: TBP and the $\mathrm{UO}_{2}\left(\mathrm{NO}_{3}\right)_{2}$ salt. 
R. Schurhammer and G. Wipff, in Separations and Processes using Supercritical Carbon Dioxide, Ed. A. S. Gopalan, C. Wai, and H. Jacobs (ACS, 2003), Vol. 860, Chap. 15, pp. 223-244.

\section{METHODS}

The simulations were performed with the modified AMBER5.0 software (35) where the potential energy is described by a sum of bond, angle and dihedral deformation energies, and pairwise additive 1-6-12 (electrostatic + van der Waals) interactions between non-bonded atoms.

$$
\begin{aligned}
U & =\sum_{\text {bonds }} K_{r}\left(r-r_{e q}\right)^{2}+\sum_{\text {angles }} K_{\theta}\left(\theta-\theta_{e q}\right)^{2}+\sum_{\text {dihedrals }} V_{n}(1+\cos n \phi) \\
& +\sum_{i<j}\left(\frac{q_{i j}}{R_{i j}}-2 \varepsilon_{i j}\left(\frac{R_{i j}^{*}}{R_{i j}}\right)^{6}+\varepsilon_{i j}\left(\frac{R_{i j}^{*}}{R_{i j}}\right)^{12}\right)
\end{aligned}
$$

The $\mathrm{UO}_{2}{ }^{2+}$ parameters are from Guilbaud and Wipff. (36) Water was represented with the TIP3P model. (37) For $\mathrm{SC}-\mathrm{CO}_{2}$, we used the parameters of Murthy et al. (38) : charges $\mathrm{q}_{\mathrm{C}}=0.596, \mathrm{q}_{\mathrm{O}}=-0.298$ e and van der Waals parameters $\mathrm{R}^{*}{ }_{\mathrm{O}}=1.692, \mathrm{R}^{*}{ }_{\mathrm{C}}=1.563 \AA$ and $\varepsilon_{\mathrm{O}}=0.165, \varepsilon_{\mathrm{C}}=0.058 \mathrm{kcal} / \mathrm{mol}$. All O-H, O-H bonds and the $\mathrm{C}=\mathrm{O}$ bonds of $\mathrm{CO}_{2}$ were constrained with SHAKE, using a time step of $2 \mathrm{fs}$. As in ref. (28), the $\mathrm{UO}_{2}\left(\mathrm{NO}_{3}\right)_{2}$ salts were constrained to remain bound and neutral in order to allow for their possible extraction to an hydrophobic medium.

The temperature was monitored by separately coupling the water, $\mathrm{CO}_{2}$ and solutes subsystems to a thermal bath at the reference temperature $(350 \mathrm{~K})$ with a relaxation time of $0.2 \mathrm{ps}$ for the solvents and $0.5 \mathrm{ps}$ for the solutes. Non-bonded interactions were calculated with a residue-based twin cutoff of $12 / 15 \AA$ for all systems, excepted for $\mathbf{D}$ and $\mathbf{E}$ for which we used a $13 \AA$ cutoff with a reaction field correction for the electrostatic interactions.
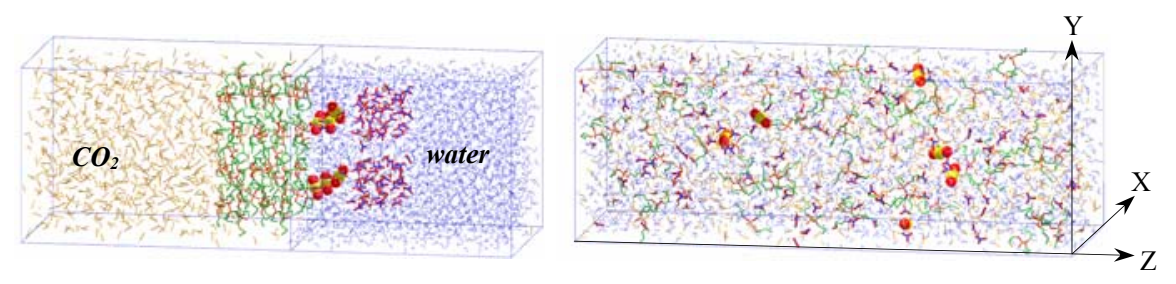

Figure 2. The simulation box, with the starting arrangement of system I (6 $\mathrm{UO}_{2}\left(\mathrm{NO}_{3}\right)_{2}+60 \mathrm{TBP}+36\left(\mathrm{HNO}_{3}, \mathrm{NO}_{3}{ }^{+} \mathrm{H}_{3} \mathrm{O}^{+}\right)$species (left). Snapshot of the mixed system (right). 
R. Schurhammer and G. Wipff, in Separations and Processes using Supercritical Carbon Dioxide, Ed. A. S. Gopalan, C. Wai, and H. Jacobs (ACS, 2003), Vol. 860, Chap. 15, pp. 223-244.

Table 1

\begin{tabular}{|c|c|c|c|c|}
\hline Systems ${ }^{a}$ & $\begin{array}{l}\text { Box size } \\
\left(\AA^{3}\right)^{b}\end{array}$ & $N_{\mathrm{CO}_{2}}+N_{\text {water }}$ & $\begin{array}{l}\text { Time } \\
\text { (ns) }\end{array}$ & $\begin{array}{c}\text { [TBP ] } \\
/[\text { acid }] \\
\left(\text { mol.L }^{-1}\right)^{c}\end{array}$ \\
\hline A Free interface & $28 \times 28 \times(28+28)$ & $241+726$ & 1.0 & - \\
\hline B $18\left(\mathrm{HNO}_{3}, \mathrm{H}_{3} \mathrm{O}^{+}, \mathrm{NO}_{3}^{-}\right)$ & $43 \times 36 \times(23+38)$ & $409+1802$ & 1.0 & $-/ 1.0$ \\
\hline C $36\left(\mathrm{HNO}_{3}, \mathrm{H}_{3} \mathrm{O}^{+}, \mathrm{NO}_{3}^{-}\right)$ & $44 \times 56 \times(31+31)$ & $813+2450$ & 1.0 & $-/ 1.6$ \\
\hline D $5 \mathrm{UO}_{2}\left(\mathrm{NO}_{3}\right)_{2}+30 \mathrm{TBP}$ & $40 \times 40 \times(43+35)$ & $595+1832$ & 3.0 & $0.72 /-$ \\
\hline E $5 \mathrm{UO}_{2}\left(\mathrm{NO}_{3}\right)_{2}+60 \mathrm{TBP}$ & $42 \times 39 \times(43+45)$ & $619+1992$ & 5.6 & $1.41 /-$ \\
\hline F $6 \mathrm{UO}_{2}\left(\mathrm{NO}_{3}\right)_{2}+30 \mathrm{TBP}+18$ acid & $42 \times 42 \times(47+47)$ & $750+2441$ & 4.0 & $0.60 / 0.7$ \\
\hline G $6 \mathrm{UO}_{2}\left(\mathrm{NO}_{3}\right)_{2}+30 \mathrm{TBP}+36$ acid & $42 \times 41 \times(57+52)$ & $905+2621$ & 4.0 & $0.51 / 0.7$ \\
\hline $\mathbf{H} 6 \mathrm{UO}_{2}\left(\mathrm{NO}_{3}\right)_{2}+60 \mathrm{TBP}+18$ acid & $43 \times 41 \times(63+56)$ & $957+2980$ & 4.0 & $0.89 / 1.2$ \\
\hline I $6 \mathrm{UO}_{2}\left(\mathrm{NO}_{3}\right)_{2}+60 \mathrm{TBP}+36$ acid & $43 \times 41 \times(63+56)$ & $957+2850$ & 5.0 & $0.89 / 1.2$ \\
\hline $\mathbf{J} \quad 6 \mathrm{UO}_{2}\left(\mathrm{NO}_{3}\right)_{2}+120 \mathrm{TBP}+36 \mathrm{acid}$ & $44 \times 43 \times(69+56)$ & $950+2800$ & 7.3 & $1.52 / 1.1$ \\
\hline
\end{tabular}

The $\mathrm{CO}_{2}$ / water interface has been built as indicated in ref. (39) starting with adjacent boxes of $\mathrm{CO}_{2}$ and pure water (Figure 2). The corresponding densities are 0.80 and 1.0 respectively. All systems were represented with 3D periodic boundary conditions, thus starting with alternating slabs of water and $\mathrm{CO}_{2}$ separated by one $\mathrm{CO}_{2} /$ water interface.

The solutes were initially placed at the interface, as shown in Figure 2. After energy minimization, MD was run at $350 \mathrm{~K}$ at constant pressure for $50 \mathrm{ps}$. This was followed by a mixing step of 1 to $1.5 \mathrm{~ns}$, during which the system was heated at $700 \mathrm{~K}$ and the electrostatic interactions were scaled down by a factor of 100 in order to enhance the mixing of hydrophobic and hydrophilic species. This lead to "chaotic mixtures" of water, $\mathrm{CO}_{2}$ and of solutes, as shown in Figure 2. The demixing simulation was then initiated be resetting the temperature to $350 \mathrm{~K}$ and the dielectric constant of the medium to 1.0.

The results have been analyzed as described in ref. (40). The interface position is instantaneously defined by the intersection of the solvent density curves. The percentage of species "near the interface" was calculated from the average number of species, which sit within a distance of $7 \AA$ from the interface, which corresponds to about half of the interfacial width. 
R. Schurhammer and G. Wipff, in Separations and Processes using Supercritical Carbon Dioxide, Ed. A. S. Gopalan, C. Wai, and H. Jacobs (ACS, 2003), Vol. 860, Chap. 15, pp. 223-244.

\section{RESULTS}

In most cases, the "demixing" process was rapid, but its rate and completeness diminished with the complexity and concentration of the solutes. For instance, the acidic system $\mathbf{C}$ (no TBP) evolved to two well separated phases in less than $0.5 \mathrm{~ns}$ while, for systems like $\mathbf{I}$ or $\mathbf{J}$, no full phase separation was achieved after 5 ns. Anyway these events remain extremely fast at the extraction experiment time scale, and we thus mainly focus on the systems at the end of the simulation. More detailed analysis can be found in ref. (41). The main features are illustrated by final snapshots, while density curves of the different species provide a statistical description during the last $0.2 \mathrm{~ns}$.

Comparison of the pure neutral water $/ \mathrm{CO}_{2}$ system to the acidic one to which uranyl salts and increasing amounts of TBP and acids have been added reveals important evolutions which are of particular significance in the context of assisted extraction of uranyl.

A

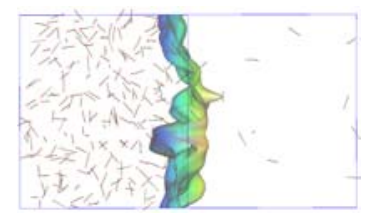

B

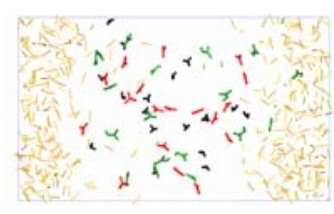

C

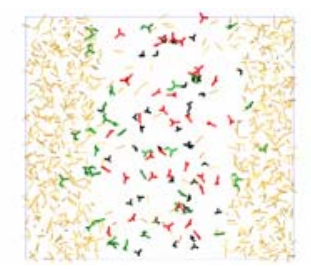

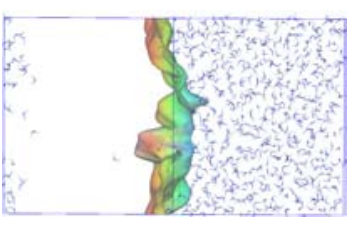
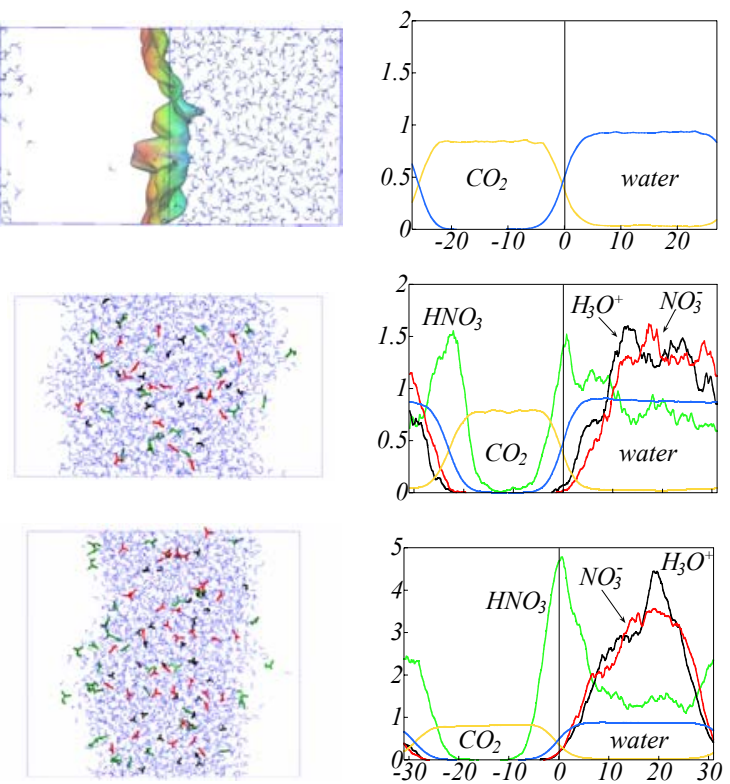

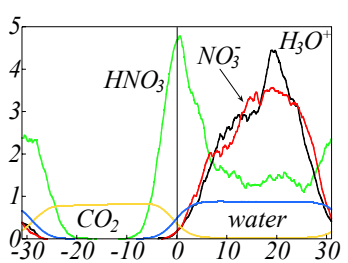

Figure 3. The neat water / $\mathrm{CO}_{2}$ interface without nitric acid (A) and with 18 $\left(\mathrm{HNO}_{3}, \mathrm{NO}_{3}^{-}, \mathrm{H}_{3} \mathrm{O}^{+}\right)$(B) or $36\left(\mathrm{HNO}_{3}, \mathrm{NO}_{3}^{-}, \mathrm{H}_{3} \mathrm{O}^{+}\right)$species (C) after 1 ns of $\mathrm{MD}$ simulation. Final snapshots (with water and $\mathrm{CO}_{2}$ solvents shown side by side, instead of superposed, for clarity) and average density curves (right; averages during the last $0.2 \mathrm{~ns}$ ). The surface of water at the interface is shown for the $\boldsymbol{A}$ system. 


\section{1- The pure water / $\mathrm{CO}_{2}$ system in $\mathrm{pH}$ neutral versus nitric acidic conditions (A - C)}

The systems A - C have been simulated with "standard" MD simulations, starting from a prebuilt interface (i.e. without mixing / demixing procedures). As shown in Figure 3, the $\mathrm{pH}$-neutral neat water $/ \mathrm{CO}_{2}$ system $\mathbf{A}$ consists of two well defined phases, separated by an interface of about $12 \AA$ thick. A few $\mathrm{CO}_{2}$ molecules diffused to water, while the $\mathrm{CO}_{2}$ phase remains dry, in agreement with the corresponding low miscibility of these liquids.

When nitric acid is added as $\left(\mathrm{HNO}_{3}, \mathrm{H}_{3} \mathrm{O}^{+} \mathrm{NO}_{3}^{-}\right)_{m}$, to form systems $\mathbf{B}(m=18)$ or $\mathbf{C}(m=36)$, the two phases remain well separated and no acid is found in the $\mathrm{CO}_{2}$ phase. The acid mainly dilutes in water, as expected, but neutral $\mathrm{HNO}_{3}$ molecules concentrate at the interface, where their concentration increases with the total nitric acid concentration (from $26 \%$ in $\mathbf{B}$ to $40 \%$ in $\mathbf{C}$ ). This contrasts with the ionic $\mathrm{NO}_{3}{ }^{-}$and $\mathrm{H}_{3} \mathrm{O}^{+}$components, which are not surface active (only $6 \%$ of them sit within $7 \AA$ from the interface).

2- Demixing simulations of pH-neutral "chaotic mixtures" of the 5 $\mathrm{UO}_{2}\left(\mathrm{NO}_{3}\right)_{2} / n$ TBP / SC-CO $/$ water (systems D and E)

During the MD simulations of "chaotic mixtures" of water, $\mathrm{CO}_{2}, \mathrm{TBP}$, $\mathrm{UO}_{2}\left(\mathrm{NO}_{3}\right)_{2}$ and $30 \mathrm{TBP}(\mathbf{D})$ or $60 \mathrm{TBP}(\mathbf{E})$, demixing occurred, leading to separated aqueous and $\mathrm{CO}_{2}$ phases and (in relation to the imposed $3 \mathrm{D}$ periodicity) to two interfaces (Figure 4). In both systems, the bulk aqueous phase finally contains some $\mathrm{CO}_{2}$ molecules, but neither TBP nor uranyl species.

Three remarkable features appear. First, TBP's mostly concentrate at the interfaces, while some fraction dilutes in $\mathrm{CO}_{2}$. At the lowest concentration (system D), only about $10 \%$ of the TBPs are in $\mathrm{CO}_{2}$, while at higher concentration (system E), about $50 \%$ are at the interface and the other $50 \%$ in $\mathrm{CO}_{2}$. Most of them are hydrogen bonded via the phosphoryl oxygen to one or two $\mathrm{H}_{2} \mathrm{O}$ molecules. One can also notice that the interface becomes more "rough" and perturbed at higher concentration of TBP and that, in no case, it is fully covered by the TBPs.

The second remarkable feature concerns the spontaneous complexation of uranyl ions by TBP at the demixing stage, forming 1:1 or 1:2 complexes, namely $\mathrm{UO}_{2}\left(\mathrm{NO}_{3}\right)_{2}(\mathrm{TBP})\left(\mathrm{H}_{2} \mathrm{O}\right)$ and $\mathrm{UO}_{2}\left(\mathrm{NO}_{3}\right)_{2}(\mathrm{TBP})_{2}$ species in which $\mathrm{UO}_{2}{ }^{2+}$ is hexacoordinated in its equatorial plane by oxygen atoms (Figure 5). The 1:1 complexes involve one $\mathrm{H}_{2} \mathrm{O}$ molecule and are therefore more hydrophilic than the 1:2 complexes which correspond to the stoichiometry of the extracted system. At the end of the simulation, all complexes are 1:2 in $\mathbf{E}$, while in $\mathbf{D}$, two are 1:1 are two are 1:2 (one remains uncomplexed), thus following trends expected from Le Chatelier principle. 
R. Schurhammer and G. Wipff, in Separations and Processes using Supercritical Carbon Dioxide, Ed. A. S. Gopalan, C. Wai, and H. Jacobs (ACS, 2003), Vol. 860, Chap. 15, pp. 223-244.

Third, as a result of complexation by TBP, all uranyl complexes sit at the interface, presumably due to two opposite features: the lipophilic character of TBP and the attraction by interfacial water molecules. Thus, the 1:1 complexes sit somewhat deeper in water than the 1:2 ones that generally sit more on the $\mathrm{CO}_{2}$ side. In the absence of TBP, the uranyl salts completely diluted in bulk water, forming $\mathrm{UO}_{2}\left(\mathrm{NO}_{3}\right)_{2}\left(\mathrm{H}_{2} \mathrm{O}\right)_{2}$ species which are too hydrophilic to approach the interfacial region, thus preventing their extraction.(29)

D

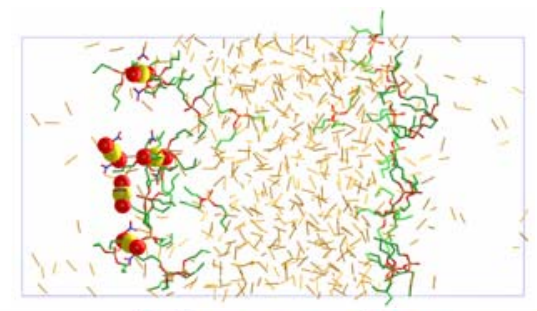

$\mathbf{E}$

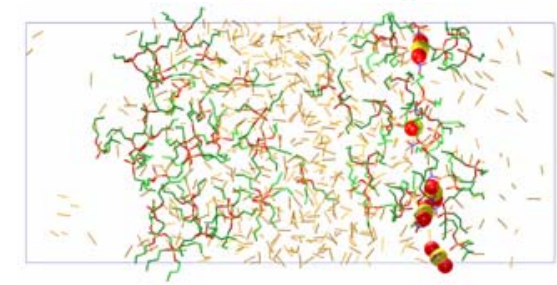

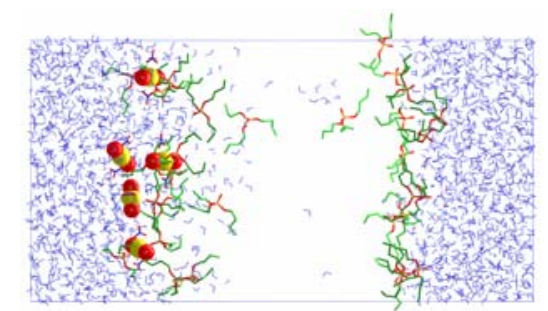

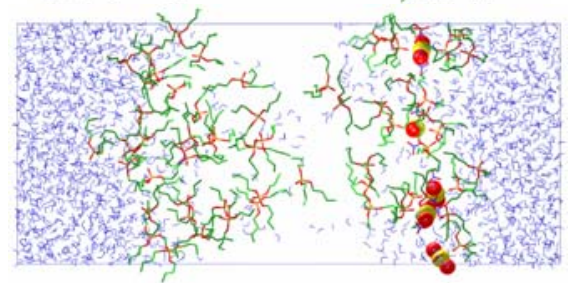

Figure 4. Demixing of the pH-neutral water / $\mathrm{CO}_{2}$ mixtures containing $5 \mathrm{UO}_{2}\left(\mathrm{NO}_{3}\right)_{2}$ and $30 \mathrm{TBP}$ (system D) or $60 \mathrm{TBP}$ (system E) at the end of the demixing simulations. Water (right) and $\mathrm{CO}_{2}$ (left) solvents shown side by side, instead of superposed, for clarity.
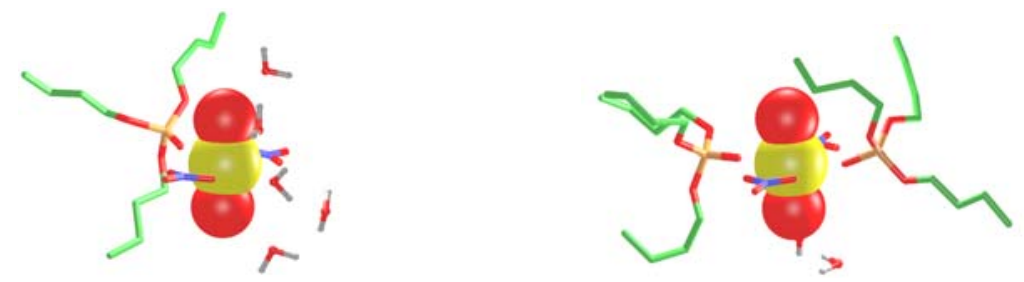

Figure 5. $\mathrm{UO}_{2}\left(\mathrm{NO}_{3}\right)_{2} \cdot \mathrm{TBP} \mathrm{H}_{2} \mathrm{O}$ (left) and $\mathrm{UO}_{2}\left(\mathrm{NO}_{3}\right)_{2}(\mathrm{TBP})_{2}$ (right) complexes formed at the water / $\mathrm{CO}_{2}$ interface during the demixing simulations of systems $\boldsymbol{D}$ or $\boldsymbol{E}$. 
R. Schurhammer and G. Wipff, in Separations and Processes using Supercritical Carbon Dioxide, Ed. A. S. Gopalan, C. Wai, and H. Jacobs (ACS, 2003), Vol. 860, Chap. 15, pp. 223-244.

\section{3- Demixing simulations of acidic "chaotic mixtures" of $6 \mathrm{UO}_{2}\left(\mathrm{NO}_{3}\right)_{2} / n$ $\mathrm{TBP} / m\left(\mathrm{HNO}_{3}, \mathrm{NO}_{3}^{-}, \mathrm{H}_{3} \mathrm{O}^{+}\right) / \mathrm{SC}-\mathrm{CO}_{2} /$ water containing systems (F-J).}

In this section, we consider systems to which nitric acid has been added, at different TBP concentrations. They all contain $6 \mathrm{UO}_{2}\left(\mathrm{NO}_{3}\right)_{2}$ salt molecules. Final snapshots are given in Figure 6 and density curves in Figure 7.

System $\mathbf{F}$ is similar to $\mathbf{D}$, i.e. contains 30 TBPs, and additional $18\left(\mathrm{HNO}_{3}, \mathrm{NO}_{3}{ }^{-}\right.$, $\mathrm{H}_{3} \mathrm{O}^{+}$) species. It also demixes and, at $2.5 \mathrm{~ns}$, the aqueous and $\mathrm{CO}_{2}$ phases are well separated. As in the above systems, most TBPs and $\mathrm{HNO}_{3}$ neutral species adsorb and spread onto these two interfaces, while five of the six $\mathrm{UO}_{2}\left(\mathrm{NO}_{3}\right)_{2}$ salts are complexed by one or two TBPs and adsorb at the interface. Most ionic $\mathrm{NO}_{3}{ }^{-}$and $\mathrm{H}_{3} \mathrm{O}^{+}$species are immersed in water. From $2.5 \mathrm{~ns}$ until the end of the simulation (4 ns), the system $\mathbf{F}$ fluctuates without major reorganization. Finally, the two interfaces are somewhat different, with different distributions of the adsorbed species. The "left interface" (Figure 6) is more flat and less perturbed than the "right one", in relation with the lower concentration of adsorbed species. The most perturbed interface contains four of the five uranyl complexes (three are 1:1 and one is 1:2), and a large concentration of $\mathrm{TBP}$ and $\mathrm{HNO}_{3}$ species (see density curves). Many of them form hydrogen bonded $\mathrm{TBP}-\mathrm{HNO}_{3}$ supermolecules (Figure 8 ), three of which moved to the $\mathrm{CO}_{2}$ side of the interface. Thus, increasing the acidity with 30 TBPs does not promote the extraction of uranyl to the $\mathrm{CO}_{2}$ phase, but induces some water/TBP/ $/ \mathrm{HNO}_{3} / \mathrm{CO}_{2}$ mixing at the border between the aqueous and $\mathrm{CO}_{2}$ phases. Such mixing should thus decrease the interfacial pressure, thus facilitating the extraction of the complexes to the $\mathrm{CO}_{2}$ phase.

Trends observed in system $\mathbf{F}$ are confirmed when the acid concentration is doubled (system $\mathbf{G}$ ). At the end of the demixing simulation, one finds a well defined interface ("left" in Figure 6) without complexes and little TBP or acid, while the right "interface" is broader, due to significant mixing of water/ $\mathrm{CO}_{2} / \mathrm{TBP} / \mathrm{acid}$, which may be viewed as a microscopic "third phase". As far as uranyl extraction is concerned, it appears that the latter is less favored in $\mathbf{G}$ than in systems C - F. Indeed, two uncomplexed uranyl salts finally remain in bulk water, as do two 1:1 complexes with TBP, while no 1:2 complexes formed. The main reason can be found in the competition of acid $v s$ uranyl interactions with TBP. Thus, about $1 / 3$ of the TBPs are hydrogen bonded with $\mathrm{H}_{3} \mathrm{O}^{+}$(Figure 8), thus preventing their complexation to uranyl. As a result, the number of neutral TBP$\mathrm{HNO}_{3}$ dimers also drops (to about 2 on the average), compared to system $\mathbf{F}$. Another difference, compared to neutral system $\mathbf{D}$ is the increased water content of the $\mathrm{CO}_{2}$ phase: the latter is no longer dry, but contains some hydrogen bonded water molecules. 
R. Schurhammer and G. Wipff, in Separations and Processes using Supercritical Carbon Dioxide, Ed. A. S. Gopalan, C. Wai, and H. Jacobs (ACS, 2003), Vol. 860, Chap. 15, pp. 223-244.
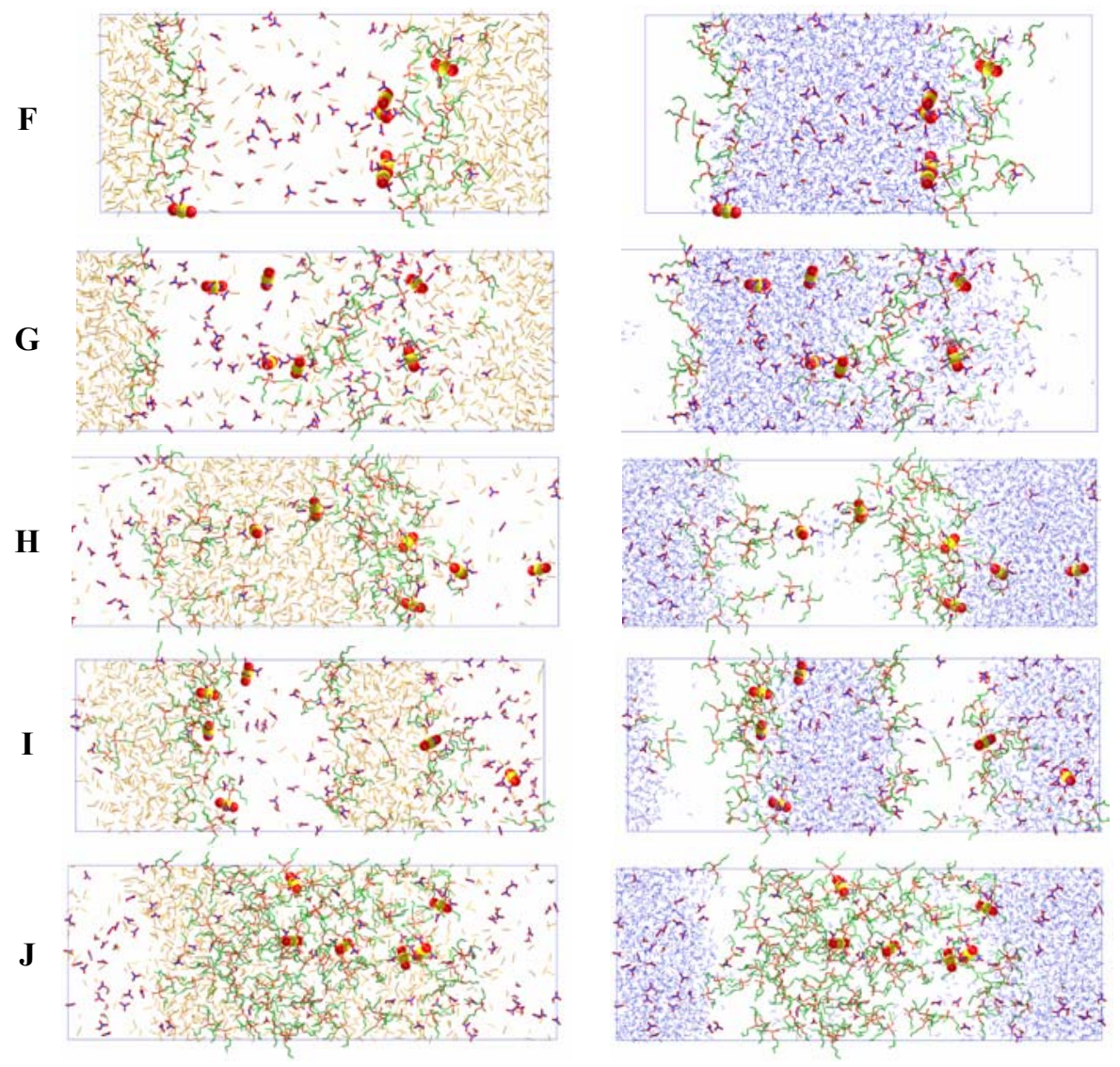

Figure 6. Demixing of the acidic water / $\mathrm{CO}_{2}$ mixtures containing $6 \mathrm{UO}_{2}\left(\mathrm{NO}_{3}\right)_{2}$, $T B P$ and nitric acid (system $\boldsymbol{F}$ to $\mathbf{J}$ ). Snapshots at the end of the demixing simulations. The water (right) and $\mathrm{CO}_{2}$ (left) solvents are shown side by side, instead of superposed, for clarity.

System $\mathbf{H}$ contains 60 TBP and $18\left(\mathrm{HNO}_{3}, \mathrm{NO}_{3}{ }^{-}, \mathrm{H}_{3} \mathrm{O}^{+}\right)$species, and thus a larger TBP / acid ratio (about two), compared to $\mathbf{F}$ or $\mathbf{G}$. After 4 ns, the resulting demixed state is similar, as far as the aqueous phase is concerned: it contains mainly the ionic components of the acid, plus one uncomplexed uranyl salt, but no TBP. Important differences appear, however, as far as the uranyl extraction is concerned (Figure 6). Indeed, the $\mathrm{CO}_{2}$ phase contains more TBP (about $20 \%$ ) than in systems $\mathbf{F}$ or $\mathbf{G}$, and most importantly, two 1:2 $\mathrm{UO}_{2}\left(\mathrm{NO}_{3}\right)_{2}(\mathrm{TBP})_{2}$ complexes, which sit beyond the cutoff distance from the interface, and thus may be considered as "extracted". Another clear evolution, concerns the disruption of the water / $\mathrm{CO}_{2}$ interfaces, which are less well defined than at lower TBP concentrations. Interfacial TBPs thus adopt "random" instead of "amphiphilic" orientations. This may be 
R. Schurhammer and G. Wipff, in Separations and Processes using Supercritical Carbon Dioxide, Ed. A. S. Gopalan, C. Wai, and H. Jacobs (ACS, 2003), Vol. 860, Chap. 15, pp. 223-244.

related to the formation of $\mathrm{TBP}-\mathrm{HNO}_{3}$ dimers near the interface, thus reducing the affinity of the polar head of TBP for water. About $1 / 3$ of the $\mathrm{HNO}_{3}$ species are thus co-extracted to the $\mathrm{CO}_{2}$ phase by TBP. Increasing the acid concentration with 60 TBP's (i.e. from system $\mathbf{H}$ to $\mathbf{I})$ leads to similar features, as far as the extent of phase separation is concerned, but one finally finds two water slabs and two $\mathrm{CO}_{2}$ slabs in the simulation box (Figure 6), thus leading to four interfaces instead of two in the above systems. This arrangement remained when the MD was pushed further for one ns (i.e. $5 \mathrm{~ns}$ for I), presumably because the cohesive solvent - solvent forces are not strong enough, and the cutoff distance is smaller than the width of these slabs. As the interfacial area is nearly doubled, compared to systems $\mathbf{E}-\mathbf{H}$, most TBPs concentrate at the interfaces. As far as uranyl complexation is concerned, one finds four 1:2 $\mathrm{UO}_{2}\left(\mathrm{NO}_{3}\right)_{2}(\mathrm{TBP})_{2}$ complexes at the interface, one 1:1 complex on the waterside of the interface, and one uncomplexed uranyl salt. Thus, like at lower concentration of TBP or acid, no complex is extracted, which hints at the importance of saturation of the interface by extractant and acid molecules to promote the extraction process. Again, about eight $\mathrm{TBP} \cdot \mathrm{HNO}_{3}$ dimers formed, half of which sitting near the interface, and the other half in $\mathrm{CO}_{2}$. Some TBP complexes with $\mathrm{H}_{3} \mathrm{O}^{+}$of up to $3: 1$ stoichiometry (TBP) $)_{3} \cdot \mathrm{H}_{3} \mathrm{O}^{+}$also sit in the interfacial region, thus attracting some $\mathrm{NO}_{3}{ }^{-}$anions from the aqueous phase to the interface.

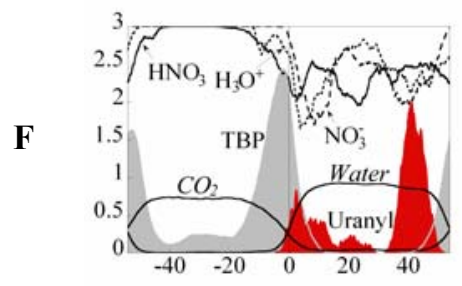

G
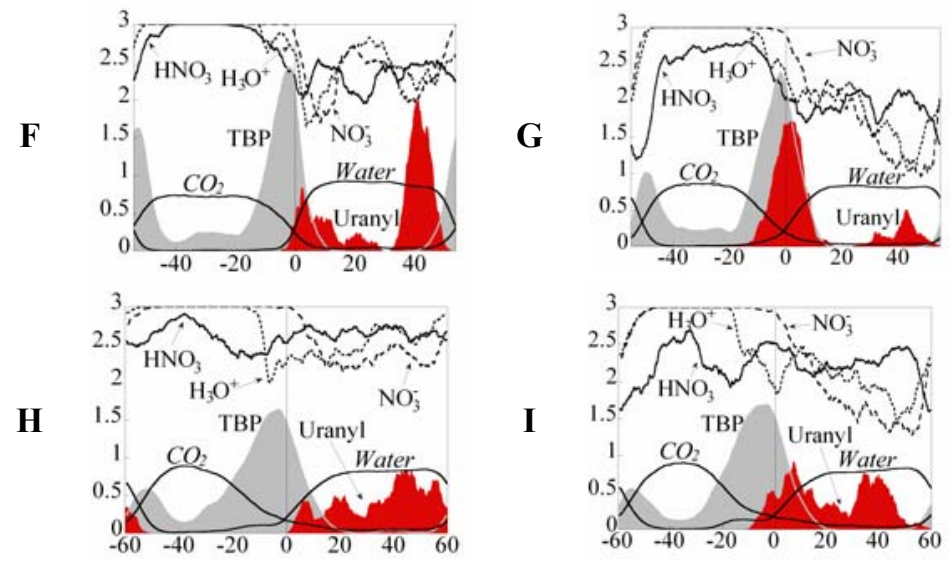

Figure 7. Demixing of the acidic water $/ \mathrm{CO}_{2}$ mixtures (systems $\boldsymbol{F}$ to $\mathbf{I}$ ). Averages density curves during the last 0.4 ns. 
R. Schurhammer and G. Wipff, in Separations and Processes using Supercritical Carbon Dioxide, Ed. A. S. Gopalan, C. Wai, and H. Jacobs (ACS, 2003), Vol. 860, Chap. 15, pp. 223-244.

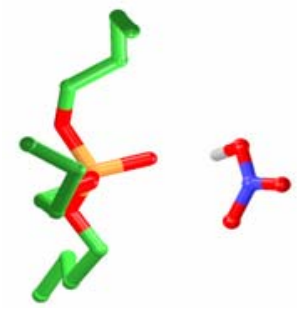

1:1 $\mathrm{TBP}^{2} \cdot \mathrm{HNO}_{3}$

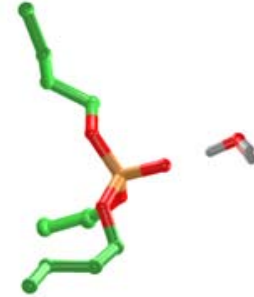

$1: 1 \mathrm{TBP}^{\circ} \mathrm{H}_{3} \mathrm{O}^{+}$

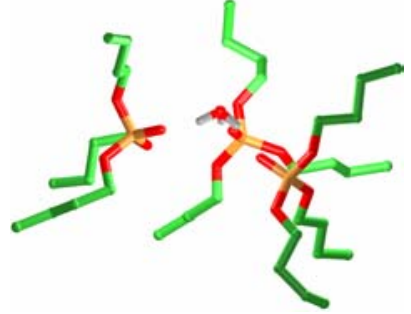

$3: 1(\mathrm{TBP})_{3} \cdot \mathrm{H}_{3} \mathrm{O}^{+}$

Figure 8. Typical TBP-acid complexes found in the $\mathrm{CO}_{2}$ phase at the end of demixing simulations.

In order to investigate the effect of box shape on the outcome of the demixing process, this system I was simulated further, by stepwise modifying the box dimensions, in order to make it less elongated at constant volume (Figure 9). After 7.5 ns of dynamics, the final box was nearly "cubic", and the solvents rearranged to form two slabs only and two interfaces. This arrangement remained for two more ns. As the final interfacial area was close to the initial one, not surprisingly, the distribution of the solutes was similar, i.e. most of them $\left(\mathrm{HNO}_{3}\right.$ and four 1:2 uranyl complexes) adsorbed at the interface, while two 1:1 complexes were on the water side of the interface. Thus, no complex was extracted to $\mathrm{CO}_{2}$.
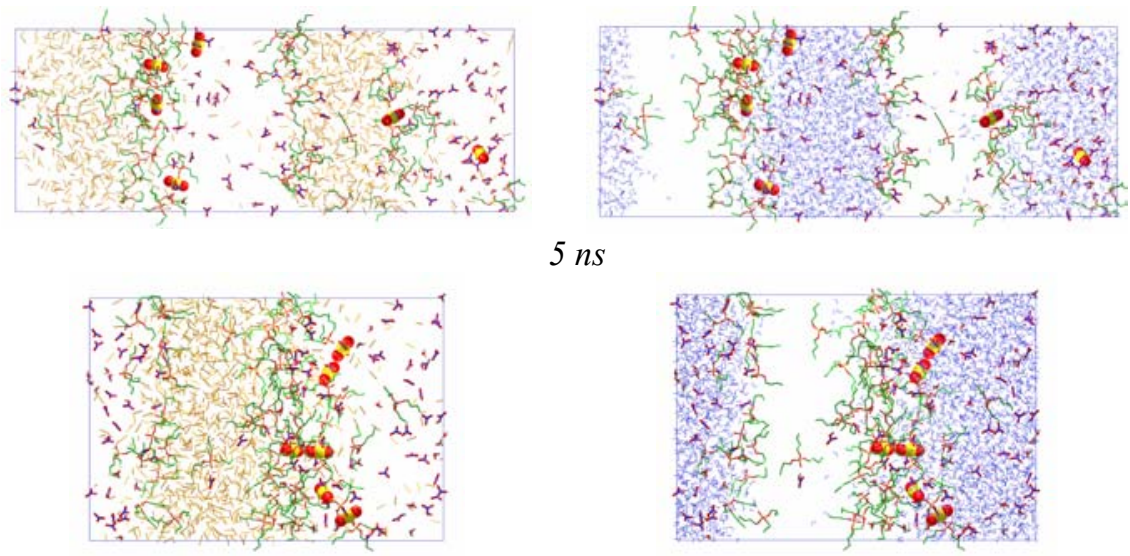

$10 n s$

Figure 9. Evolution of system I as the box z-dimension is reduced (total volume is conserved). 
The most concentrated system we simulated is $\mathbf{J}$, which contains 120 TBPs and $1.1 \mathrm{M}$ acid, i.e. $36\left(\mathrm{HNO}_{3}, \mathrm{H}_{3} \mathrm{O}^{+} \mathrm{NO}_{3}^{-}\right)$species. Thus, the TBP concentration reaches about $30 \%$ of the total volume. During the demixing simulation, the separation of the aqueous phase was very slow (about $5 \mathrm{~ns}$ ) and until the end of the simulation $(7.3 \mathrm{~ns})$, it contained only $\mathrm{NO}_{3}{ }^{-}$and $\mathrm{H}_{3} \mathrm{O}^{+}$ions. Yet, the final picture is quite different from the above ones as far as the $\mathrm{CO}_{2}$ component, the interfaces, and uranyl extraction are concerned. The organic phase now consists of a binary mixture of TBP and $\mathrm{CO}_{2}$ and surprisingly, the TBP concentration at the water boundaries is quite lower (<15\%) than in other simulated systems. More than $85 \%$ of the TBPs are thus in the supercritical phase, where about $30 \%$ of them are hydrated. The organic phase now contains neutral and ionic forms of the acid, strongly interacting with TBPs. About $50 \%$ of $\mathrm{H}_{3} \mathrm{O}^{+}$ions sit in the organic phase and form (TBP) ${ }_{3} \mathrm{H}_{3} \mathrm{O}^{+}$complexes (Figure 8), without dragging nitrate counterions. Also about $40 \%$ of $\mathrm{HNO}_{3}$ acid species form 1:1 adducts with TBP. Thus, the organic phase is strongly mixed, with a high ion content. Of particular significance is that it also contains five of the six uranyl complexes, forming 1:2 $\mathrm{UO}_{2}\left(\mathrm{NO}_{3}\right)_{2}(\mathrm{TBP})_{2}$ species which can thus be considered as extracted. A sixth 1:2 complex sits near the interface, i.e. on the pathway for extraction. Thus, system $\mathbf{J}$ is the most "efficient one", as far as uranyl extraction is concerned. When compared to other systems in which TBP and acid are less concentrated, it allows one to better understand at the microscopic level the requirements for assisted extraction to SC$\mathrm{CO}_{2}$.

\section{DISCUSSION AND CONCLUSION}

We report MD simulations on the extraction of uranyl by TBP to supercritical $\mathrm{CO}_{2}$ in acidic conditions. They point to a number of analogies with the water / "oil" interfacial systems simulated in standard conditions, where "oil" was modeled by chloroform, and with the acid-free systems: the aqueous and organic phases generally form distinct phases, separated by a liquid-liquid interface, onto which extractant molecules and their complexes adsorb. With $\mathrm{CO}_{2}$ as organic phase, the interface is somewhat thicker, in relation with the higher mobility of the $\mathrm{CO}_{2}$ molecules under supercritical conditions. Simulations of the neat interface under several thermodynamic conditions have recently been reported.(42) From the size of the simulated systems (less than $80 \AA$ in the $\mathrm{z}$-direction), it cannot be concluded whether one is dealing with macroscopic or microscopic interfaces only (e.g. at the periphery of microdroplets, microemulsions, or micelles $(24,43-46))$. We believe however that this interface is an important feature for the mechanism of ion extraction. Species adsorbed at the interface (lipophilic anions, extractants and their complexes, solvent modifiers like fluorinated additives) reduce the interfacial tension, and thus lower the energy required for the complex to migrate to the supercritical phase. The local dielectric constant at the interface is also smaller than in the source (aqueous) phase, thus enhancing the stability of the cation complexes. 
R. Schurhammer and G. Wipff, in Separations and Processes using Supercritical Carbon Dioxide, Ed. A. S. Gopalan, C. Wai, and H. Jacobs (ACS, 2003), Vol. 860, Chap. 15, pp. 223-244.

As pointed out previously, amphiphilic topologies are not mandatory for interfacial activity, as even "quasi-spherical" ions like $\mathrm{AsPh}_{4}{ }^{+}$or $\mathrm{BPh}_{4}{ }^{-},(47)$ bicylic cryptates $(48,49)$ or even tetracharged tetrahedral tetraammonium cages (50) also concentrate at the interface. Acids are also somewhat surface active, as shown here for nitric acid, and, a fortiori, for weaker acids used in solvent extraction (e.g. picric acid, carboxylic acids). The conjugated bases may also adsorb at the interface, therefore creating a negative potential which attracts the hard cations near the interface and facilitate their capture by interfacial ligands. Such a "synergistic interfacial anion effect" likely operates in the enhanced lanthanide cation extraction by CMPO in the presence of picrate anions.(51) In the systems reported here, nitrate anions behave differently as they mostly dilute in water instead of concentrating near the interface.

A different process is observed here in the absence of such lipophilic anions. We see that large amounts of TBP are necessary to promote the formation and extraction of the complexes. TBP indeed acts not only as a complexant and surface active molecule, but also as a co-solvent with $\mathrm{CO}_{2}$. Interestingly, in our simulations, uranyl complexation takes place during the metastable demixing step, i.e. after the aqueous and organic phases were forced to mix. Otherwise, the salts would not approach the interface enough to be captured by the interfacial TBP molecules. The $\mathrm{UO}_{2}\left(\mathrm{NO}_{3}\right)_{2}(\mathrm{TBP})_{2}$ complexes form at the border of the two forming phases during the demixing process and, as phase separation goes on, finally adsorb at the interface, instead of spontaneously migrating to $\mathrm{CO}_{2}$. In our simulation, one clearly sees that high concentrations of TBP (about $30 \%$ in volume) are needed to promote the migration to the $\mathrm{CO}_{2}$ phase. This increases the concentration of extractable 1:2 complexes and, more importantly, changes the nature of the interface, which becomes a "third phase" region where $\mathrm{CO}_{2}, T B P$, some acid and complexes mix. This heterogeneous microenvironment stabilizes the complexes, which can be considered as "extracted" from water.

As far as the effect of acidity is concerned, we generally find that the acid competes with the complexation of uranyl, due, to the formation of strong hydrogen bonds between TBP and $\mathrm{HNO}_{3}$ or $\mathrm{H}_{3} \mathrm{O}^{+}$species. Protonated TBP $\cdot \mathrm{H}^{+}$species, not considered here, are also likely to form and to be surface active. Thus, a large excess of TBP is required (e.g. in system $\mathbf{J}$ ), to efficiently complex uranyl. This may seem in contradiction with experimental data, according to which the uranyl distribution ratio $\mathrm{D}$ between the aqueous and $\mathrm{CO}_{2}$ phases increases with the increased concentration of nitric acid.(52) These data follow the global extraction equation (I) which assumes that the uncomplexed uranyl salt is mostly dissociated and hydrated in the aqueous phase:

$$
\left(\mathrm{UO}_{2}{ }^{2+}\right)_{\mathrm{aq}}+2 \mathrm{TBP}_{\mathrm{CO} 2}+2\left(\mathrm{NO}_{3}^{-}\right)_{\mathrm{aq}} \longrightarrow\left(\mathrm{UO}_{2}\left(\mathrm{NO}_{3}\right)_{2}(\mathrm{TBP})_{2}\right)_{\mathrm{CO} 2}
$$

They also follow expected effects of added ions (e.g. $\mathrm{Li}^{+} \mathrm{NO}_{3}{ }^{-}$) via the reduction of the water activity ("salting-out effect"). The apparent discrepancy comes from our 
R. Schurhammer and G. Wipff, in Separations and Processes using Supercritical Carbon Dioxide, Ed. A. S. Gopalan, C. Wai, and H. Jacobs (ACS, 2003), Vol. 860, Chap. 15, pp. 223-244.

choice to model uranyl by its neutral $\mathrm{UO}_{2}\left(\mathrm{NO}_{3}\right)_{2}$ salt instead of $\mathrm{UO}_{2}{ }^{2+}$, in order allow for its possible extraction. In fact, it is very difficult to predict the status of ion pairs in pure solutions (see e.g. ref (53) for lanthanide salts in acetonitrile) and, a fortiori, at liquid-liquid interfaces. The formation of neutral salts may also be too slow to occur at the simulated time scales. Thus, this facet cannot be addressed by our simulations. In this context, the spontaneous formation of uranyl complexes with TBP is remarkable, and points to the importance of (micro)-heterogeneities of the systems and metastable conditions to form the complexes and promote their extraction to organic or supercritical phases.

Acknowledgements. The authors are grateful to IDRIS, CINES and Université Louis Pasteur for computer resources and to PRACTIS for support. RS thanks the French Ministry of Research for a grant. This work has been stimulated by the EEC FIKWCT2000-0088 project. Acknowledgement is made to the Donors of The Petroleum Research Fund, administered by the American Chemical Society, for partial travel support for WG to Orlando. 
R. Schurhammer and G. Wipff, in Separations and Processes using Supercritical Carbon Dioxide, Ed. A. S. Gopalan, C. Wai, and H. Jacobs (ACS, 2003), Vol. 860, Chap. 15, pp. 223-244.

\section{References}

1- Laintz, K. E.; Wai, C. M.; Yonker, C. R.; Smith, R. D., Anal. Chem. 1992, 64, 2875.

2- Wai, C. M.; Wang, S., J. Chromatogr. A 1997, 785, 369-383.

3- Smart, N. G.; Carleson, T.; Kast, T.; Clifford, A. A.; Burford, M. D.; Wai, C. M., Talanta 1997, 44, 137-150.

4- Babain, V.; Murzin, A.; Shadrin, A.; Smart, N. 5th Meeting on Supercritical Fluids, 1998, 155-160.

5- Lin, Y.; Brauer, R. D.; Laintz, K. E.; Wai, C. M., Anal. Chem. 1993, 65, 25492551.

6- Ashraf-Khorassani, M.; Combs, M. T.; Taylor, L. T., J. Chromatogr. A 1997, 774, 37-49.

7- Lin, Y.; Wai, C. M.; Jean, F. M.; Brauer, R. D., Environ. Sci. Technol. 1994, 28, 1190.

8- Wai, C. M.; Kulyako, Y.; Yak, H.-K.; Chen, X.; Lee, S.-J., Chem. Commun. 1999, 2533-2534.

9- Toews, K. L.; Smart, N. G.; Wai, C. M., Radiochim. Acta 1996, 75, 179-184.

10- Carrott, M. J.; Waller, B. E.; Smart, N. G.; Wai, C. M., Chem. Commun. 1998, 373-374.

11- Samsonov, M. D.; Wai, C. M.; Lee, S. C.; Kulyako, Y.; Smart, N. G., Chem. Comm. 2001, 1868-1869.

12- Lin, Y.; Smart, N. G.; Wai, C. M., Environ. Sci. Technol. 1995, 29, 2706-2708.

13- Meguro, Y.; Iso, S.; Takeishi, H.; Yoshida, Z., Radiochim. Acta 1996, 75, 185 191.

14- Addleman, R. S.; Wai, C. M., Phys. Chem. Chem. Phys. 1999, 1, 783-790.

15- Addleman, R. S.; Carrott, M. J.; Wai, C. M., Anal. Chem. 2000, 72, 4015-4021.

16- Dehgani, F.; Wells, T.; Cotton, N. J.; Foster, N. R., J. Supercrit. Fluids 1996, 9, 263.

17- Joung, S. N.; Yoon, S. J.; Kim, S. Y.; Yoo, K. P., J. Supercritic. Fluids 2000, 18, 157-166.

18- Smart, N. G.; Carleson, T. E.; Elshani, S.; Wang, S.; Wai, C. M., Ind. Eng. Chem. Res. 1997, 36, 1819-1826.

19- Erkey, C., J. Supercrit. Fl. 2000, 17, 259-287.

20- Choppin, G. R.; Nash, K. L., Radiochimica Acta 1995, 70/71, 225-236.

21- Horwitz, E. P.; Kalina, D. G.; Diamond, H.; Vandegrift, G. F.; Schultz, W. W., Solv. Extract. Ion Exch. 1985, 3, 75-109.

22- den Auwer, C.; Lecouteux, C.; Charbonnel, M. C.; Madic, C.; Guillaumont, R., Polyhedron 1998, 16, 2233-2238.

23- den Auwer, C.; Charbonnel, M. C.; Presson, M. T.; Madic, C.; Guillaumont, R., Polyhedron 1998, 17, 4507-4517. 
R. Schurhammer and G. Wipff, in Separations and Processes using Supercritical Carbon Dioxide, Ed. A. S. Gopalan, C. Wai, and H. Jacobs (ACS, 2003), Vol. 860, Chap. 15, pp. 223-244.

24- Jensen, M.; Chiarizia, R.; Ferraro, J. R.; Borkowski, M.; Nash, K. L.; Thiyagajan, P.; Littrell, K. C. ISEC 2002, 2002, 1137-1142.

25- Schurhammer, R.; Wipff, G., New J. Chem. 2002, 26, 229-233.

26- Vayssière, P.; Wipff, G., Phys. Chem. Chem. Phys. 2003, 5, 127-135.

27- Schnitzer, C.; Baldelli, S.; Campbell, D. J.; Shultz, M. J., J. Phys. Chem. 1999, 103, 6383-6386.

28- Baaden, M.; Schurhammer, R.; Wipff, G., J. Phys. Chem. B 2002, 106, 434-441.

29- Berny, F.; Schurhammer, R.; Wipff, G., Inorg. Chim. Acta; Special Issue 2000, 300-302, 384-394.

30- Watarai, H., Trends in Analytical Chemistry 1993, 12, 313-318.

31- Wipff, G.; Lauterbach, M., Supramol. Chem. 1995, 6, 187-207.

32- Berny, F.; Muzet, N.; Schurhammer, R.; Troxler, L.; Wipff, G. in Current Challenges in Supramolecular Assemblies, NATO ARW Athens; G. Tsoucaris Ed.; Kluwer Acad. Pub., Dordrecht, 1998; pp 221-248.

33- Berny, F.; Muzet, N.; Troxler, L.; Wipff, G. in Supramolecular Science: where it is and where it is going; R. Ungaro; E. Dalcanale Eds.; Kluwer Acad. Pub., Dordrecht, 1999; pp 95-125 and references cited therein.

34- Schurhammer, R.; Berny, F.; Wipff, G., Phys. Chem. Chem. Phys. 2001, 3, 647656.

35- Case, D. A.; Pearlman, D. A.; Caldwell, J. C.; Cheatham III, T. E.; Ross, W. S.; Simmerling, C. L.; Darden, T. A.; Merz, K. M.; Stanton, R. V.; Cheng, A. L.; Vincent, J. J.; Crowley, M.; Ferguson, D. M.; Radmer, R. J.; Seibel, G. L.; Singh, U. C.; Weiner, P. K.; Kollman, P. A., AMBER5, University of California, San Francisco 1997.

36- Guilbaud, P.; Wipff, G., J. Mol. Struct. THEOCHEM 1996, 366, 55-63.

37- Jorgensen, W. L.; Chandrasekhar, J.; Madura, J. D.; Impey, R. W.; Klein, M. L., J. Chem. Phys. 1983, 79, 926-936.

38- Murthy, C. S.; K. Singer; McDonald, I. R., Mol. Phys. 1981, 44, 135-143.

39- Muzet, N.; Engler, E.; Wipff, G., J. Phys. Chem. B 1998, 102, 10772-10788.

40- Lauterbach, M.; Engler, E.; Muzet, N.; Troxler, L.; Wipff, G., J. Phys. Chem. B 1998, 102, 225-256.

41- Schurhammer, R., Thesis, 2001, Université Louis Pasteur de Strasbourg.

42- da Rocha, S. R. P.; Johnston, K. P.; Westacott, R. E.; Rossky, P. J., J. Phys. Chem. B 2001, 105, 12092-12104 ; da Rocha, S.R.P.; Johnston, K. P.; Rossky, P. J., J. Phys. Chem. B 2002, 106, 13250-13261.

43- Erlinger, C.; Gazeau, D.; Zemb, T.; Madic, C.; Lefrançois, L.; Hebrant, M.; Tondre, C., Solv. Extract. Ion Exch. 1998, 16, 707-738.

44- Lefrançois, L.; Delpuech, J.-J.; Hébrant, M.; Chrisment, J.; Tondre, C., J. Phys. Chem. B 2001, 105, 2551-2564.

45- Osseo-Asare, K., Advances in Colloid Interface Sci. 1991, 37, 123-173.

46- Stoyanov, E. S., Phys. Chem. Chem. Phys. 1999, 1, 2961-2966.

47- Schurhammer, R.; Wipff, G., New J. Chem. 1999, 23, 381-391. 
R. Schurhammer and G. Wipff, in Separations and Processes using Supercritical Carbon Dioxide, Ed. A. S. Gopalan, C. Wai, and H. Jacobs (ACS, 2003), Vol. 860, Chap. 15, pp. 223-244.

48- Jost, P.; Galand, N.; Schurhammer, R.; Wipff, G., Phys. Chem. Chem. Phys. 2002, 4, 335-344.

49- Jost, P.; Chaumont, A.; Wipff, G., Supramol. Chem., in press.

50- Chaumont, A.; Wipff, G., J. Comput. Chem. 2002, 23, 1532-1543.

51- Naganawa, H.; Suzuki, H.; Tachimori, S.; Nasu, A.; Sekine, T., Phys. Chem. Chem. Phys. 2001, 2509-2517.

52- Meguro, Y.; Iso, S.; Yoshida, Z., Anal. Chem. 1998, 70, 1262-1267.

53- Baaden, M.; Berny, F.; Madic, C.; Wipff, G., J. Phys. Chem. A 2000, 104, 76597671. 